How to cite: Tudose, T., Moldovan, F. (2020) Is the Indian Summer Present in Romania? 2020 "Air and WaterComponents of the Environment" Conference Proceedings, Cluj-Napoca, Romania, p. 47-58, DOI: 10.24193/AWC2020_05.

\title{
IS THE INDIAN SUMMER PRESENT IN ROMANIA?
}

\author{
Traian TUDOSE ${ }^{1}$, Florin MOLDOVAN ${ }^{1}$
}

DOI: 10.24193/AWC2020_05

\begin{abstract}
Is the Indian summer present in Romania? The first part of the study refers to the occurrence of the Indian summer events in Romania, over the 1961-2019 period. The second part analyses the Indian summer event recorded in Romania in October 2019. The datasets used for the first part were daily maximum and minimum temperatures recorded in the past 59 years at 23 climatological weather stations, divided into 6 regions. Regarding the methodology, first step was to determine the annual and seasonal occurrence of the first frost for each weather station, and then the presence of the warm spells (WSs), based on the percentile threshold method. So, we could determine WSs with different types of intensity (using the $90^{\text {th }}, 95^{\text {th }}, 98^{\text {th }}$ percentile), and durations. For the Indian summer event recorded between 12 and 28 October 2019, daily maximum temperatures from 157 weather stations were compared to absolute maximum temperatures over the period 1961-2018. Synoptic conditions were determined using weather charts at sea level pressure, geopotential height and temperature of 925, 850, 700 and $500 \mathrm{hPa}$.

The main finding is: Indian summer events are frequent in the Carpathians and in the Northern, Central and the Western regions of Romania, especially in November, followed by October; no matter the intensity, short duration events have high number of cases, and severe and extremely severe events were registered in the past 20 years; the Indian summer event from October 2019 was influenced by synoptic and local conditions, as well. Overall the Indian summer is not present in Romania every year, but it is more frequent and intense in the last 20 years.
\end{abstract}

Keywords: Indian summer, warm spell, percentile, regions, Romania

\section{INTRODUCTION}

The Indian Summer phenomenon refers to a period of warm days and cool nights associated mostly with clear skies and lack of wind, that appear in the late autumn or early winter (Morrow, 1911). The Online Etymology Dictionary (2019) defines the term as "spell of warm, dry, hazy weather after the first frost", while weather historian William Deedler (1996) considers it as "an abnormally warm and dry weather period, varying in length that comes in the autumn time of the year, usually in October or November". In North America, the phenomenon is associated to a

\footnotetext{
${ }^{1}$ Babeş-Bolyai University, Faculty of Geography, Cluj-Napoca, Romania, ttraiant@gmail.com flormold@yahoo.com
} 
period of warm and calm weather in mid or late autumn (International Meteorological Dictionary, WMO, 1992), while in New England, a true "Indian Summer" is considered to be a warm spell that comes after a killing frost and a period of normally cool weather. It can be concluded that the occurrence of Indian summer (IS) is related to a period of high temperature values (Heat Waves - HWs, and/or Warm Spells - WSs) recorded in the late autumn or early winter.

The expression "Indian Summer" was for the first time used in the current sense in the late 1770s, by J. Hector St. John de Crevecoeur (US), but the origin of the term is uncertain (Sweeting, 2003). It is very common in the northeastern United States, and it seems to be related to the way the American Indians use this opportunity to increase their winter stores. In England, a similar phenomenon is known as All-hallown summer (English folklore), a period of unseasonable warmth that occurs in the eve of All Saints Day, mentioned by Shakespeare, and more frequently today, known as St. Luke's summer, St. Martin's summer, Old Wives' summer (http://glossary.ametsoc.org/wiki/Indian_summer), while in Central and Eastern Europe, is called "old women's summer" (https://en.wikipedia.org/wiki/Indian_summer).

HWs and WSs are defined as a number of consecutive days in which the extreme temperatures are high above normal, depending of the time of the year they occur (WMO, 2016, Sfîcă et al., 2017). Some of the studies regarding this issue consider the term of HWs more appropriate to be used for the warm season (late spring, summer, early autumn), while WSs is preferred for events registered in the cold season (late autumn, winter, early spring) (Sfîcă et al., 2017, Croitoru et al., 2018).

The present study is focused on the occurrence of IS in Romania in the autumn months, over a period of 59 years, as a spell of warm after the first frost. The study is divided into two sections: the first one analyses the occurrence of IS in Romania over the period 1961-2019, using 23 climatological weather stations; the second part is a case study of the IS event registered in Romania from 12 to 28 October, 2019, using data from 157 weather stations.

\section{DATA AND METHODS \\ 2.1. Data used}

In order to determine the presence of IS for the period 1961-2019, daily maximum and minimum temperatures from 23 climatological weather stations were used. The datasets were freely downloaded from http://data.gov.ro/dataset (for the period 1961-2016), and http://www.meteomanz.com (for the period 2017-2019), and had no more than $5 \%$ of missing data (WMO, 2018). The data were quality checked (Alexander and Herold, 2016). In the case study of October 2019, all available weather stations of Romania were used (157 stations, Figure 1), and the daily datasets of maximum temperatures were downloaded from http://www.meteomanz.com. Also, synoptic weather charts at sea level pressure, geopotential height and temperature of $925,850,700$ and $500 \mathrm{hPa}$ accessed from 
http://www.wetter3.de/archiv_gfs_dt.html were analyzed, in order to determine the synoptic conditions generating the Is event from October 2019.

As the Carpathian Mountains induces spatial differences of climate variables, the territory of Romania was divided into 6 regions: East, South-East, South, West, North and Center, and The Carpathians. These regions correspond to the historical regions of Romania: East to Moldavia, South-East to Dobrudja, South to Muntenia and Oltenia, West to Banat and Crişana, North and Center to Maramureş and Transylvania.

All the weather stations used in the study were distributed into regions mentioned above, according to their position (Figure 1).

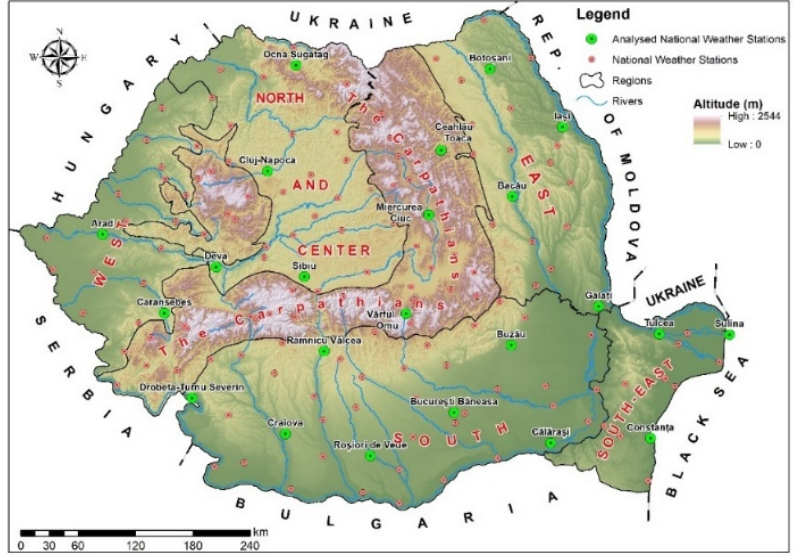

Fig. 1. Spatial distribution of weather stations within tho rooions usod in tho studv,

\subsection{Methods}

As the IS is considered to be a spell of warm in the autumn months after the first frost, the first step was to determine the occurrence of the first frost of every autumn, for each weather station, over a period of 59 years (1961-2019), using daily minimum temperatures. After that, for the intensity of the WSs, we used percentile threshold method as it can easily allow comparison, no matter the altitude of the weather stations and the regions they are located. The $90^{\text {th }}, 95^{\text {th }}$, and $98^{\text {th }}$ percentile was calculated for each calendar day of autumn months for the based period 1981-2010, and compared to the maximum temperatures registered in the same day of the 1961-2019 period (Alexander et al., 2006). Based on these, we determined moderate WSs, when the maximum temperature of the day was equal or exceeded the $90^{\text {th }}$ percentile, severe WSs, when the maximum temperature was equal or exceeded the $95^{\text {th }}$ percentile, and extremely severe WSs, when the maximum temperature was equal or exceeded the $98^{\text {th }}$ percentile.

Another criterion of a WS is the duration threshold, which means a number of consecutive days in which a threshold of intensity is achieved (Croitoru, 2014). In the present study, the threshold duration was established at 3 consecutive days. In the end, IS events of moderate, severe, and extremely severe intensity for each of the 23 weather stations were determined.

In order to analyze the IS event from 12 to 28 October 2019, the methodology was as it follows: first we determined the length of the event from October 2019, using the data from 23 weather stations mentioned above; second, the daily maximum temperature recorded to each weather station between 12 and 28 October 2019 was compared to the absolute maximum temperature recorded at that weather station, for the same day of the period 1961-2018. If a weather station equaled or exceeded the absolute maximum 
temperature of the day, for 3 consecutive days, a WS was considered to be present. This method allowed us to determine the duration and spatial extent of the phenomena, not its intensity. It might be a subject of discussion, but only 23 climatological weather station were not enough to emphasize the extent of the analyzed IS event.

\section{RESULTS AND DISCUSSIONS}

The IS events registered in Romania in autumn months in the 1961-2019 period remarked differences in numbers and intensity of the events between regions, (Table 1). The number of moderate Is events is between 1, in the South-East region, and 74, in the Carpathians. For the east part of the South-East region, the absolute number is between 1 and 5 events, as a consequence of the influence induced by the proximity of the Black Sea. In the north part of the region, where the influence of the body water is not that high, the number of events for the entire period is up to 23 cases.

Table 1. Cumulative number of cases and maximum number of days/case of IS events, depending on their intensity, over the period 1961-2019

\begin{tabular}{|c|c|c|c|c|c|c|c|}
\hline \multirow[t]{2}{*}{ Region } & \multirow{2}{*}{$\begin{array}{c}\text { Weather } \\
\text { station }\end{array}$} & \multicolumn{3}{|c|}{$\begin{array}{c}\text { Number of cases } \\
\text { M-moderate; S- severe; } \\
\text { ES-extremely severe }\end{array}$} & \multicolumn{3}{|c|}{ Maximum number of days per case/recorded yr. } \\
\hline & & $\mathbf{M}$ & $\mathbf{S}$ & ES & Moderate & Severe & $\begin{array}{c}\text { Extremely } \\
\text { severe }\end{array}$ \\
\hline \multirow{4}{*}{ East } & Botoşani & 35 & 24 & 10 & $9 / 2010$ & $\mathbf{9} / 2010$ & $\mathbf{5} / 1963$ \\
\hline & Iaşi & 31 & 21 & 15 & $\mathbf{1 3} / 2010$ & $\mathbf{1 2} / 2010$ & 9/2010 \\
\hline & Bacău & 29 & 24 & 12 & $\mathbf{1 0} / 2009$ & $8 / 2010$ & $6 / 2010$ \\
\hline & Galați & 20 & 12 & 6 & $\mathbf{1 2} / 2010$ & $12 / 2010$ & $8 / 2010$ \\
\hline \multirow{3}{*}{$\begin{array}{l}\text { South- } \\
\text { East }\end{array}$} & Tulcea & 23 & 14 & 6 & $13 / 2019$ & $10 / 2019$ & $5 / 1969$ \\
\hline & Sulina & 1 & 0 & 0 & $3 / 1980$ & 0 & 0 \\
\hline & Constanța & 5 & 3 & 2 & 6/1969,1980 & $\mathbf{5} / 1969$ & $5 / 1969$ \\
\hline \multirow{7}{*}{ South } & Buzău & 28 & 14 & 6 & $8 / 2010$ & $7 / 1969,2010$ & $5 / 1969$ \\
\hline & București Băneasa & 27 & 17 & 5 & $13 / 2010$ & $7 / 2002$ & $5 / 1969$ \\
\hline & Călăraşi & 22 & 9 & 2 & $8 / 2002$ & $7 / 2002$ & $4 / 2002$ \\
\hline & Roşiorii de Vede & 28 & 14 & 3 & $8 / 2010$ & $7 / 1969$ & $\mathbf{5} / 1969,1990$ \\
\hline & RâmnicuVâlcea & 27 & 13 & 6 & $7 / 2002,2009,2010$ & $7 / 2010$ & $\mathbf{4} / 2002,2010,2013$ \\
\hline & Drobeta-Tr. Severin & 18 & 9 & 5 & $10 / 2015$ & $7 / 2010$ & $6 / 2010$ \\
\hline & Craiova & 28 & 14 & 6 & 11/2009 & 6/2009, 2010 & $6 / 2010$ \\
\hline \multirow{2}{*}{ West } & Caransebeș & 28 & 15 & 9 & $16 / 2019$ & $14 / 2019$ & $8 / 2019$ \\
\hline & Arad & 29 & 19 & 7 & $15 / 2019$ & $14 / 2019$ & $11 / 2019$ \\
\hline \multirow{4}{*}{$\begin{array}{l}\text { North } \\
\text { and } \\
\text { Center }\end{array}$} & Ocna Şugatag & 37 & 20 & 10 & $15 / 2019$ & $14 / 2019$ & 10/2018, 2019 \\
\hline & Cluj-Napoca & 34 & 16 & 5 & $14 / 2019$ & $14 / 2019$ & $10 / 2019$ \\
\hline & Deva & 38 & 17 & 6 & $17 / 2019$ & $15 / 2019$ & $\mathbf{1 0} / 2013,2018$ \\
\hline & Sibiu & 39 & 21 & 11 & $\mathbf{1 5} / 2019$ & $13 / 2019$ & 9/2019 \\
\hline \multirow{3}{*}{$\begin{array}{l}\text { The } \\
\text { Carpat } \\
\text { hians }\end{array}$} & CeahlăuToaca & 62 & 35 & 20 & $15 / 2018$ & $14 / 2018$ & $10 / 2019$ \\
\hline & Miercurea Ciuc & 68 & 44 & 20 & $\mathbf{1 5} / 2019$ & $8 / 2019$ & $7 / 2010,2013$ \\
\hline & Vârful Omu & 74 & 48 & 24 & $14 / 2018$ & $14 / 2018$ & $7 / 2019$ \\
\hline
\end{tabular}

For the South Romania, moderate intensity of the IS events is between 18 and 28 cases, Drobeta-Turnu Severin weather station registering the lowest number of events due to its location near the Danube River. The West region recorded less than 30 cases for the entire period, while the Eastern Romania had between 20 and 35 events. In the North and Center region were registered between 34 and 39 events, while in the mountain area, between 62 and 74 cases of moderate intensity of the IS 
events were recorded (Table 1). It can be concluded that IS events are influenced by the presence of the body waters (that generates high evaporation rates and lower temperature values), and by local climate and synoptic conditions (thermal inversions, in the case of the Carpathians, and the North and Center regions).

Severe IS events presents almost the same structure like the moderate ones, but they are less frequent. The absolute number of cases is between 0 in the South-East region and 48 events in the mountain area (Table 1). It can be easily observed that severe intensity events represent almost $70 \%$ of the IS cases in the east part of the country, $62 \%$ in the mountain area, and $60 \%$ in the West region, while the other regions have only up to $50 \%$ of the total cases.

Extremely severe IS events have the lowest frequency of all, and the absolute number of events recorded was no higher than 24 cases. Less than 10 events for the entire period were recorded in the South-East, South and West regions, while most of the weather stations from the East and the North and Center regions recorded more than 10 events. It must be noted that the highest number of cases in lowlands were recorded at Iassi ( 15 cases/entire period), while in the mountain area, it reached up to 24 cases at Vârful Omu weather station (Table 1).

The maximum number of days for an IS case for each weather station emphasizes the magnitude of weather condition that generated the event, and it can highlight the local conditions within each region. For the moderate intensity of IS events, the maximum number is 17 days/event; the lowest number of days were recorded in the South-East region (between 3 and 13 days/event), the highest number in the West, and North and Center regions (between 14 and 17days/event), while South and East regions had no more than 13 days/event (Table 1). In the case of severe and extremely severe intensity, the structure is the same, but the number of days/event is lower (no more than 11 days/event in the case of extremely severe intensity) (Table 1).

Regarding the year of maximum number of days/event, it can be said that the high intensity and persistence of WS from 2019 generated the event in the West, North and Center regions, also in the depressions of the mountain area, no matter the intensity; the WS from 2002 determined moderate and severe intensity and long duration of IS in the South and East regions, but extremely severe events for the last two regions were determined by the WS from 1969 (Table 1). It can be concluded that WSs which occurred in the last two decades of the studied period generated the longest IS events in Romania.

Regardless the intensity, in Romania the IS events were recorded mostly in November, followed by October. An exception is for the Carpathians, and the North and Center regions, where the first frost usually appears in September. Moderate intensity of the IS events decrease with the increase of the number of events for most of regions, except the South-East, influenced by the presence of a large water bodies (Figure 2). Severe intensity has the same distribution, while extremely severe intensity events are recorded more often in November. For the West and, respectively, the Carpathians region, extremely severe IS events occur more often in October, too, while in the mountain area are registered at high rates in September as well (Figure 2).

The annual distribution of IS events highlights regional particularities according to their duration and intensity. Moderate intensity of IS events of 3, 4 and 5 days/case 
were recorded in the East region, with a relative uniform distribution through the studied period; events of 6 days/case were registered more often in the first half of the period, while those of 7 days/case and higher were present in the first and last decade of the period (Figure 3).
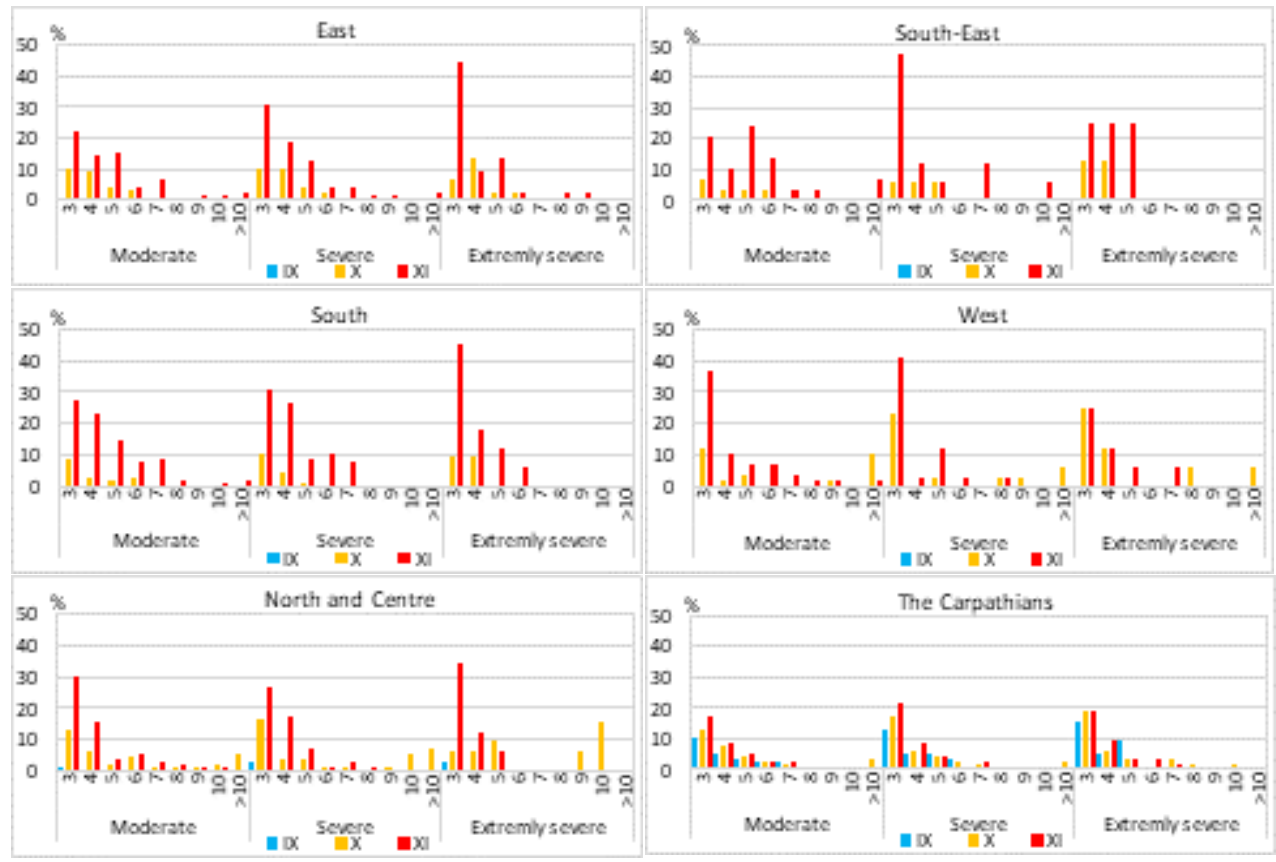

\section{Figure 2. Monthly frequency (\%) of IS events duration (no. of days) according to their intensity, over the period 1961-2019}

The IS events of severe intensity were registered over the entire period, and those of long duration (over 8 days/case) were produced after the year 2010 (Figure 3). Events of extremely severe intensity were more often registered in the first and the last decade of the analyzed period, with a high frequency of short duration (Figure 3).

There were observed differences in annual distributions of IS cases between the east part of the South-East region, where the shore of the Black Sea is present, and the central-north part of the region. The proximity of the large body water of the Black Sea determined a delay in appearance of the first frosty night in autumn, so the total number of IS events was low, did not exceed 6 days/case, and were not recorded in the last two decades (Sulina and Constanţa weather stations, Figure 4). For the central-north part of the region, IS cases of moderate intensity, lasting up to 7 days/case, were recorded in the first half of the analyzed period, while those of 10 days/case and more, very few in number, occurred after 2010; severe events for the 3 days/case class occurred in the first half of the studied period, for the case of 4 days/case class, in the last two decades, and for the 7 days/case class randomly; 
extremely severe events were recorded in the first half of the period (3 days/case), and in the last two decades (4 days/case) (Tulcea weather station, Figure 4).

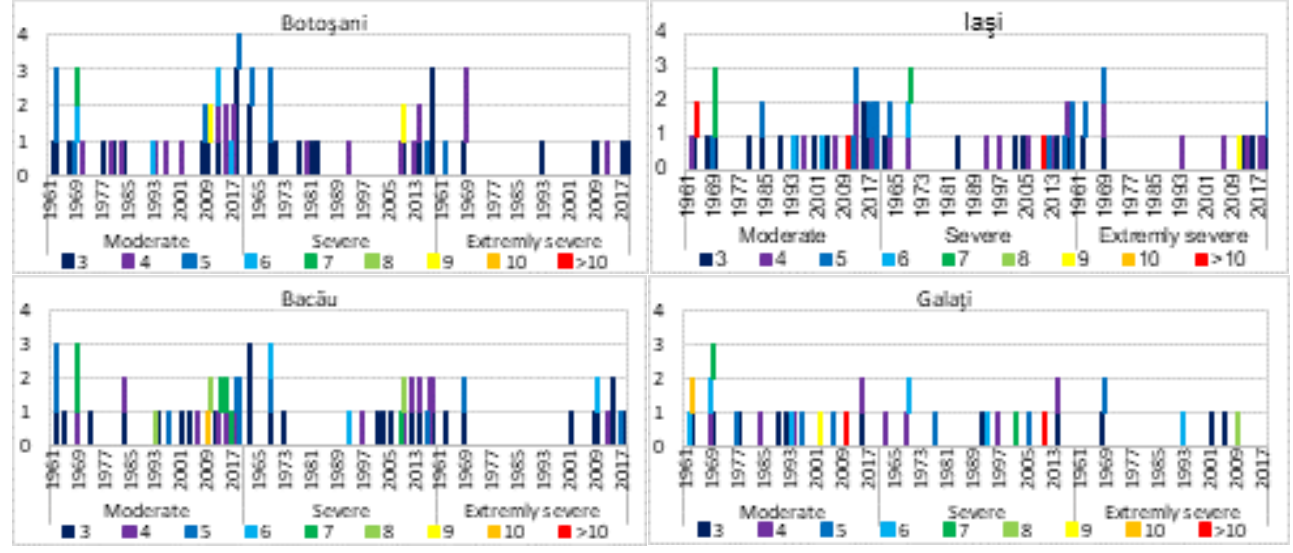

Figure 3. Annual distribution of IS case duration (days/case) by intensity, at the weather stations in the East region, over the period 1961-2019

For the South region of the country, moderate intensity of IS cases lasting 3 and 4 days/case are relatively evenly distributed over the analyzed period, a higher number of cases being recorded after 1990; events of 5 days/case were more numerous in the period 1961-1990, while events of more than 5 days/case do not have a uniform temporal distribution, but were recorded more often after the year 2000 (Figure 5). Severe intensity events of 3 days/case characterize the first half of the analyzed period, events of 4 days/case are more often in the second half of the period, and events lasting more than 4 days/case were recorded generally after 2000 (Figure 5). Extremely severe events were no more than 7 days/case, and were recorded mostly in the last two decades of the analyzed period (Figure 5).
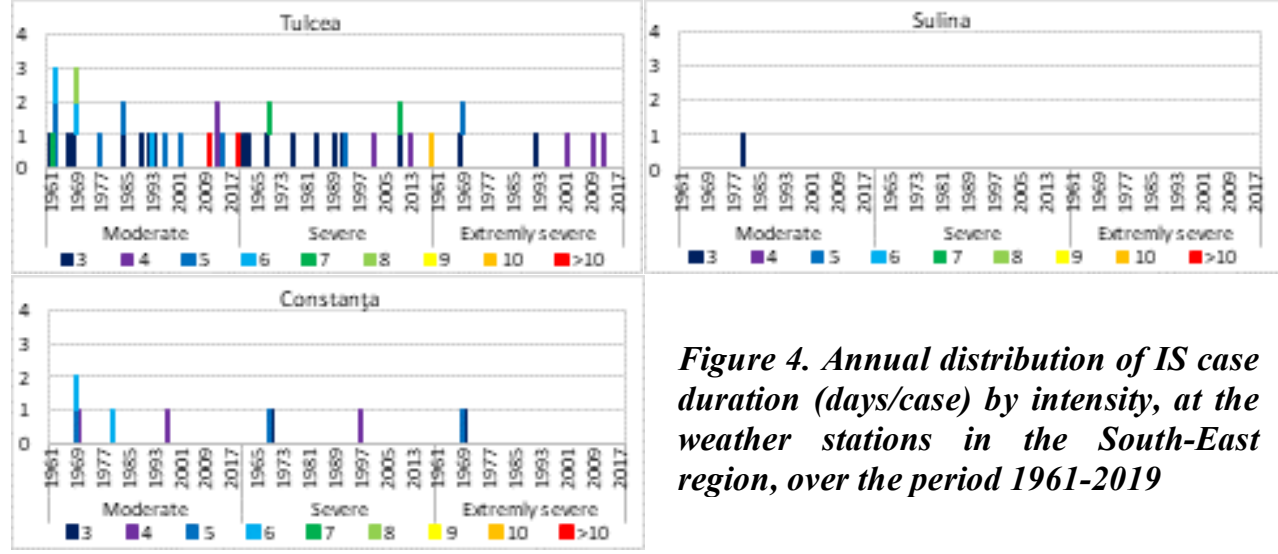

Figure 4. Annual distribution of IS case duration (days/case) by intensity, at the weather stations in the South-East region, over the period 1961-2019

Moderate intensity of IS events of 3 days/case, in the West region, recorded a relatively uniform distribution, events of 4 to 6 days/case presented uneven distribution, and those over 7 days/case were recorded more often after the year 1990 (Figure 6). Severe intensity events have almost the same annual distribution as the 
moderate ones, only events over 6 days/case were recorded in the last decade, while extremely severe events have uneaven time distribution, long duration of days/case, most of the events being recorded after the year 2010 (Figure 6).
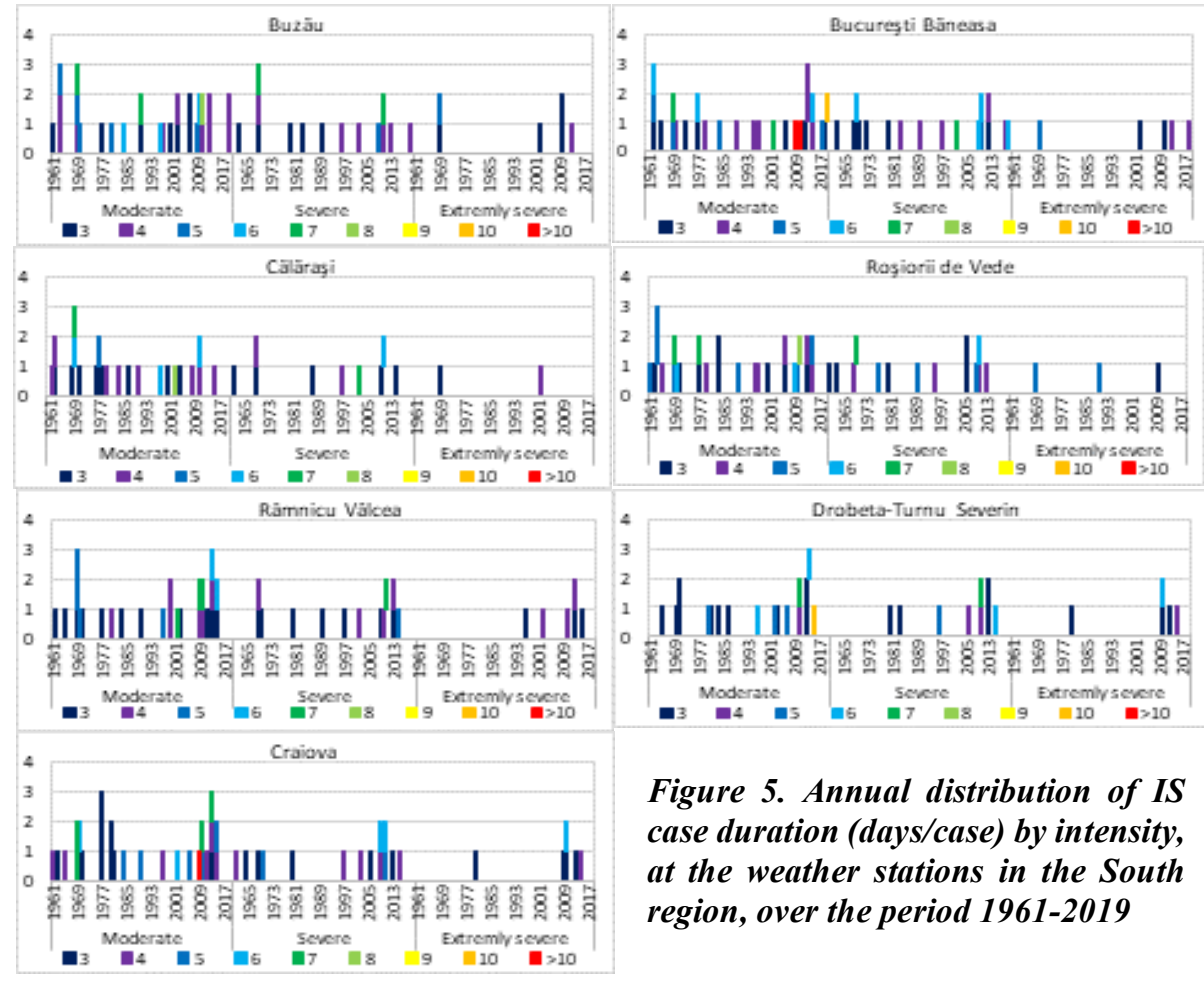

Figure 5. Annual distribution of IS case duration (days/case) by intensity, at the weather stations in the South region, over the period 1961-2019

The North and Center region have moderate intensity of IS events of 3, 4 and 5 days/case relatively evenly distributed over the studied period, but the number of cases reduces with the increase of number of days/case, while events lasting 6 days/case and higher, were recorded mostly after the year 2000 (Figure 7).

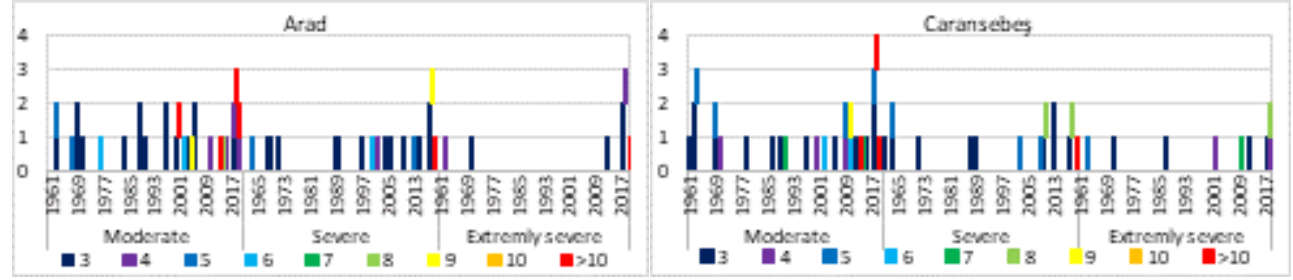

Figure 6. Annual distribution of IS case duration (days/case) by intensity, at the weather stations in the West region, over the period 1961-2019

Events of severe intensity lasting 3 days/case were recorded more often in the second half of the analyzed period, and those of 4 days/case are evenly distributed; events lasting 5 and 6 days/case were registered in the last two decades, and the longer ones (up to over 10 days/case) were registered more recently, predominantly after the year 2010 (Figure 7). The IS events of extremely severe intensity generally 
occurred after the year 1990, the longer the number of days/case was, the most recently they appeared.

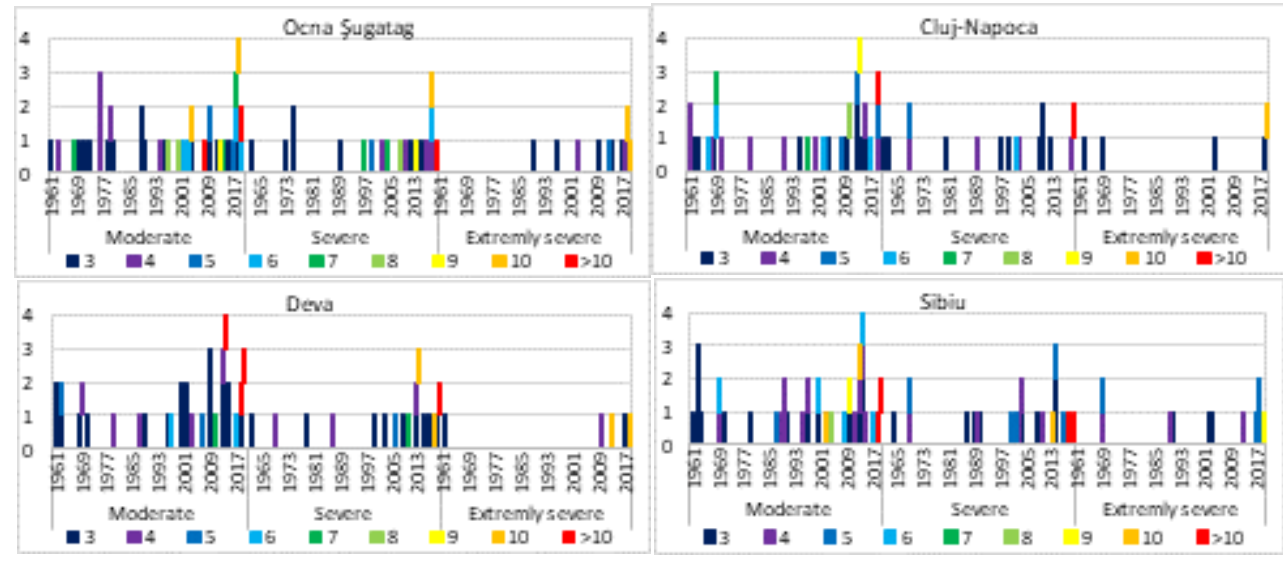

Figure 7. Annual distribution of IS case duration (days/case) by intensity, at the weather stations in the North and Center region, over the period 1961-2019

In the Carpathians region, the annual distribution of IS events emphasize some major features: events lasting 3 to 5 days/case have a relatively evenly distribution regardless the intensity; for the clases of 6 to 8 days/case, the number of cases decreases with the increase of duration, regardless the intensity, and are more frequent after the year 2003; the duration of 10 days/case and higher are registered mostly after the year 2010, no matter the intensity class (Figure 8).
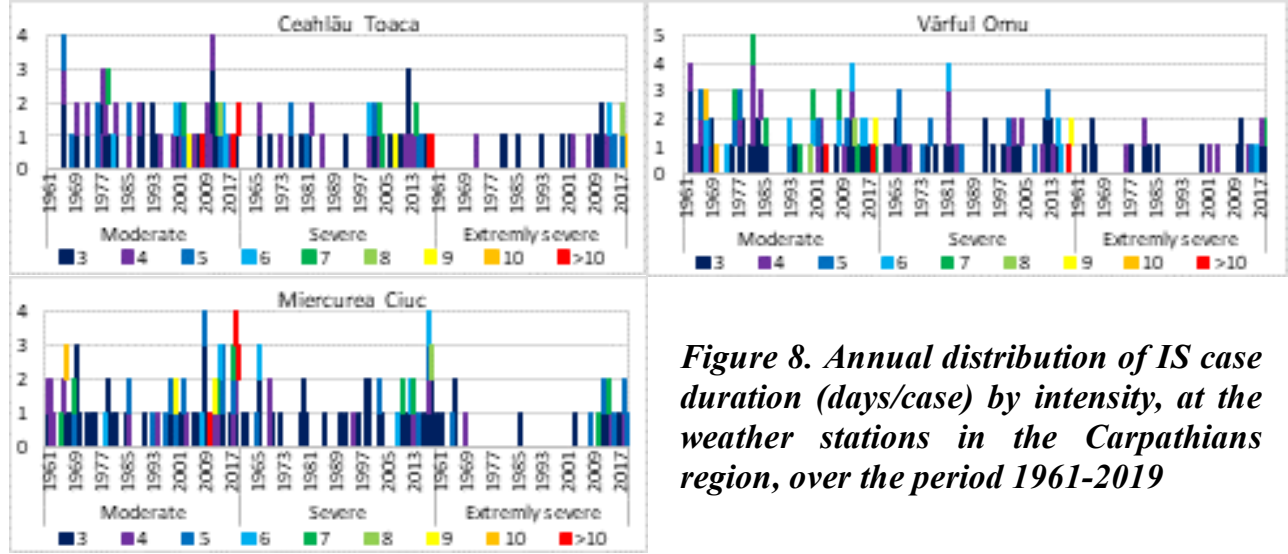

Figure 8. Annual distribution of IS case duration (days/case) by intensity, at the weather stations in the Carpathians region, over the period 1961-2019

\section{Synoptic conditions generating IS event from 12 to 28 of October 2019.}

Sea level pressure maps indicate that on 12 of October 2019 the southern half of the European continent was under the influence of a mobile anticyclone detached from the Azores High ridge, moving eastward over the Mediterranean basin. From October 18, the ridges of Azores High and Eastern European High unite, generating a high-pressure field (over of $1020 \mathrm{hPa}$ ). Beginning with October 22, in the western part of the Mediterranean basin a cyclonic structure is formed and moves slowly to 
west of Italy Peninsula where, on October 26, it is occluded (Fig. 9). All this time, in the south-east of Europe, the sea level pressure did not go under the value of 1020 $\mathrm{hPa}$. From October 28, this pressure decreases as a result of a cold front system which is approaching from the north-west.
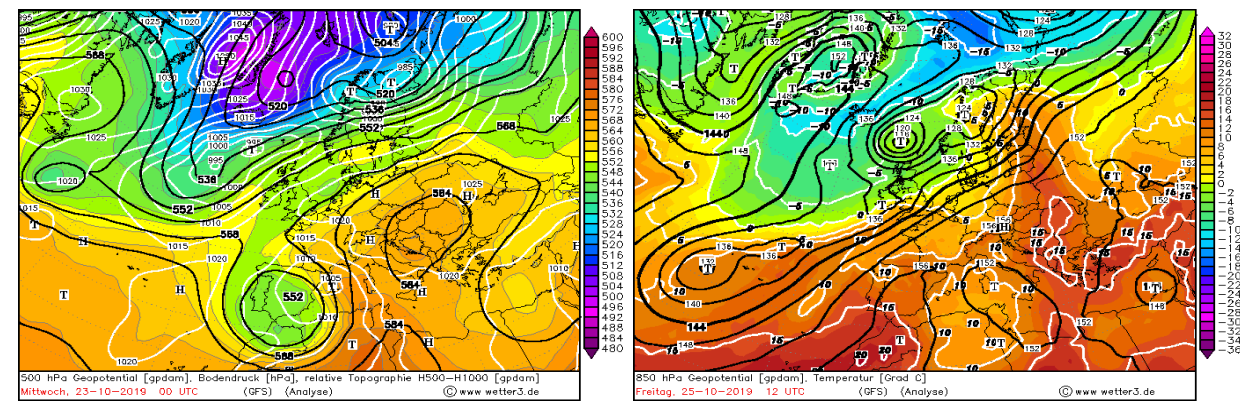

Figure 9. Geopotential height at 500 hPa (gpdam), Sea Level Pressure (hPa) and

Thickness 500-1000 hPa (gpdam) on October 23, 2019, 00 UTC (left), Geopotential height (gpdam) and Temperature $\left({ }^{\circ} \mathrm{C}\right)$ at $850 \mathrm{hPa}$ on October 25, 2019, 12 UTC (right) (source: http://www1.wetter3.de/archiv)

Starting with October 11, at $500 \mathrm{hPa}$ geopotential level, a ridge extends over the western half of Europe, gradually advancing towards east, generating a southwestern air circulation. The geopotential ridge intensifies on October 20, and after 3 days, an upper level high-pressure system of 584 gpdam is positioned over Romania, generating a southern air circulation (Figure 9). In the next days, the geopotential ridge presents slight daily variations, but it maintains itself at values around 580 gpdam, until October 27, when it begins to weaken and retreat to the Eastern Europe.

The $850 \mathrm{hPa}$ geopotential level indicates a warm air advection over the south-east of Europe, air temperature rising over the Romania from $5^{\circ} \mathrm{C}$ on October 11, to 14$15^{\circ} \mathrm{C}$ on October 13 . Between 16 and 20 of October, the air temperature of $850 \mathrm{hPa}$ level is decreasing to $10-12^{\circ} \mathrm{C}$, as the thermal ridge moves eastward. From October 21 , the thermal and geopotential ridge intensifies, so the temperature rises up to 14$15^{\circ} \mathrm{C}$, with a maximum extend on October 25 , when the temperature reached $16^{\circ} \mathrm{C}$, and the axis of the thermal ridge has a north-south orientation over the Romania (Figure 9). From October 27, the thermal ridge gradually weakens and retreats to the south-east, as the polar air advances from the north-west.

The case study of IS event registered from 12 to 28 of October 2019, highlights some regional manifestations determined by local conditions. For the East region, where 20 weather stations were analyzed, only one case of the event was recorded, in the north-west part of it (Rădăuţi weather station), while in the South-East region the event was not present at all. Regarding the South region, characterized by a large variety of landforms (plain area in the southern half, respectively plateau and hilly area in the north and north-west part of the region), the event had short duration (maximum 5 days, between 20 and 24 of October), being registered only at 15 of the 43 analyzed weather stations (Table 2), and was mostly present in the east and north part of the region (area of landforms over $300 \mathrm{~m}$ altitude). The features of the event 
in mentioned regions was determined by the presence in the lower troposphere, near the ground surface, of a thermal inversion with the formation of Stratus clouds or/and fog during the nights and mornings of the analyzed period, as hourly synoptic data available on www.meteomanz.com website showed. This was the reason why daily maximum temperatures recorded were not so high (Table 2).

Table 2. Number of weather stations that registered daily maximum temperature (TX) from October 12-28, 2019 equal or higher than the absolute maximum temperature (abs. $T X)$ of the same day from 1961-2018 period, depending on the number of consecutive days they were registered, and extreme daily maximum temperatures (extr. TX) between 12-28 October 2019, registered in each region

\begin{tabular}{|c|c|c|c|c|c|c|c|c|c|c|c|}
\hline \multirow[t]{2}{*}{ Region } & \multirow{2}{*}{$\begin{array}{c}\text { No. of } \\
\text { weather } \\
\text { stations } \\
\text { used }\end{array}$} & \multicolumn{8}{|c|}{$\begin{array}{c}\text { No. of weather stations where TX from October } 12-28,2019 \text { equaled or } \\
\text { exceeded abs. TX of the same day from 1961-2018 period, depending } \\
\text { on the number of consecutive days }\end{array}$} & \multirow[t]{2}{*}{ Total } & \multirow{2}{*}{$\begin{array}{c}\text { Extr. TX } \\
\left({ }^{\circ} \mathrm{C}\right)\end{array}$} \\
\hline & & $\begin{array}{c}3 \\
\text { days }\end{array}$ & $\begin{array}{c}4 \\
\text { days }\end{array}$ & $\begin{array}{c}5 \\
\text { days }\end{array}$ & $\begin{array}{c}6 \\
\text { days }\end{array}$ & $\begin{array}{c}7 \\
\text { days }\end{array}$ & $\begin{array}{c}8 \\
\text { days }\end{array}$ & $\begin{array}{c}9 \\
\text { days }\end{array}$ & $\begin{array}{c}10 \\
\text { days }\end{array}$ & & \\
\hline East & 20 & 1 & - & - & - & - & - & - & - & 1 & $21.9-26.7$ \\
\hline South-East & 14 & - & - & - & - & - & - & - & - & 0 & $19.4-26.5$ \\
\hline South & 43 & 9 & 4 & 2 & - & - & - & - & - & 15 & $20.9-28.5$ \\
\hline West & 18 & - & 2 & 6 & 5 & 4 & - & 1 & - & 18 & $25.7-30.6$ \\
\hline North and Center & 24 & 5 & 2 & 6 & 3 & 4 & - & 1 & - & 21 & $24.2-27.0$ \\
\hline The Carpathians & 38 & 1 & 4 & 7 & 10 & 8 & 3 & 1 & 1 & 35 & $13.9-29.5$ \\
\hline
\end{tabular}

In the West, the Carpathians, and North and Center regions, the event had the largest spatial extension and duration, as the thermal inversion near the surface was weak, so the daily maximum temperatures registered in these regions were high (Table 2).

\section{CONCLUSIONS}

The study of IS events between 1961 and 2019 in Romania, at 23 climatological weather stations, remarks regional differences in the spatial extension, duration and intensity. Regarding the number of cases, the event is more frequent in the Carpathians, the North and Central, and West regions, and the less frequent in the South-East region, where a major factor of its occurrence is the influence of local conditions. The highest number of cases was recorded in November, followed by October, while in September it occurred only in the regions where the first frost is recorded in early autumn.

Moderate intensity of IS events present higher number of cases for small durations, their frequency decreases with the increasing of duration, and generally long durations were recorded in the last two decades of the studied period. Severe and extremely severe events are shorter as duration and were recorded more often after the year 2000, except for the Eastern region, where they were recorded as well in the 1961-1970 period. As a fact, the South-East region presents generally short durations of the events, regardless the intensity.

The IS event of October 2019 was determined by the presence of an upper-level geopotential ridge in the South-East of Europe, generating a warm air advection in the lower troposphere, and a high atmospheric pressure field at the sea level. In the 
East, South-East and South regions, the synoptic configuration and local conditions determined the appearance of Stratus clouds and/or fog, resulting a small number of IS days. In the West, the Carpathians, and the North and Central regions, the small extension of thermal inversion and Stratus clouds or fog, generated high spatial extension and duration of the IS event.

It can be concluded that IS phenomenon is present in Romania in the late autumn months, especially in the mountain areas, the West, North and Central regions. This phenomenon is not present every year, but it is more frequent and has greater intensity and duration especially after the year 2000 .

\section{REFERENCES}

1. Alexander, L., Herold, N. (2016), ClimPACT2 Indices and Software, https://github.com/ARCCSS-extremes/climpact2. Accessed on 10.12.2019.

2. Croitoru, A.-E. (2014), Heat waves. Concept, definitions and methods used to detect. Riscuri şi Catastrofe, Casa Cărţii de Ştiinţă Cluj-Napoca, 15(2), 25-32.

3. Croitoru, A.-E., Piticar, A., Sfîcă, L., Roșca, C.-F., Tudose, T., Horvath, Cs., Minea, I., Ciupertea, A.-F., Scripcă, S., Harpa, G. (2018), Extreme temperature and precipitation events in Romania, Editura Academiei Române, București.

4. Deedler, W, (1996), Just What Is Indian Summer And Did Indians Really Have Anything To Do With It? [online], URL: https://web.archive.org/web/20141009005228/http://www.crh.noaa.gov/dtx/stories/isummer.php. Accessed on 23.11.2019.

5. Morrow, J. (1911), Indian Summer. Monthly Weather Review, 39, 469-470.

6. Sfîcă, L., Croitoru, A.-E., Iordache, I., Ciupertea, A.-F. (2017), Synoptic Conditions Generating Heat Waves and Warm Spells in Romania. Atmosphere, 8(3), 50 https://doi.org/10.3390/atmos8030050.

7. Sweeting, A.W. (2003), Beneath the Second Sun: A Cultural History of Indian Summer, New Hampshire,ISBN 978-1-58465-314-1, 14-15.

8. WMO (1992), International Meteorological Dictionary, $2^{\text {nd }}$ edition, Geneva.

9. WMO (2016), Guidelines on the definition and monitoring of extreme weather and climate events. Draft version - first review by TT-DEWCE (Dec 2015). [online], URL: http://www.wmo.int/pages/prog/wcp/ccl/opace/opace2/documents/DraftversionoftheGui delinesontheDefinitionandMonitoringofExtremeWeatherandClimateEvents.pdf. Accessed on 20.11.2019.

10. WMO (2018), Guide to Climatological Practices. [online], URL: https://library.wmo.int/doc_num.php?explnum_id=5541. Accessed on 05.12.2019.

11. http://data.gov.ro/dataset. Accessed on 03.12.2019.

12. https://en.wikipedia.org/wiki/Indian_summer. Accessed on 17.11.2019.

13. http://glossary.ametsoc.org/wiki/Indian_summer. Accessed on 15.02.2019.

14. http://www1.wetter3.de/archiv_gfs_dt.html. Accessed on 06.01.2020.

15. https://www.etymonline.com/. Accessed on 23.11.2019.

16. http://www.meteomanz.com/. Accessed on 03.12.2019. 